\title{
THE COMPARATIVE DISTRIBUTION OF ENKEPHALIN, DYNORPHIN AND SUBSTANCE P IN THE HUMAN GLOBUS PALLIDUS AND BASAL FOREBRAIN
}

\author{
S. N. HABER* and S. J. WATSON† \\ *Department of Anatomy, University of Rochester School of Medicine, Rochester, NY 14642, U.S.A.; \\ †Mental Health Research Institute, University of Michigan Medical School, Ann Arbor, MI 48109, \\ U.S.A.

\begin{abstract}
Three neuropeptides, enkephalin, dynorphin, and substance $\mathbf{P}$ appear in the globus pallidus in a unique pattern termed woolly fibers as described previously [Haber and Nauta (1983) Neuroscience 9, 245-260]. The comparative distribution of these fibers are described in the human globus pallidus and basal forebrain area. The results show two main points: (1) The human globus pallidus is a larger, more intricately shaped structure than previously thought, invading several limbic-related basal forebrain regions. (2) There are differences in the distribution patterns of the neuropeptides described, so that they are found in overlapping, but not matching regions.

The relationship between the peptide distribution and what is known about the functional (limbic vs motor) circuitry of the region is discussed.
\end{abstract}

It has recently been demonstrated that in the primate central nervous system, enkephalin-like immunoreactivity appears in a distinct pattern characterized by networks of long ribbon-like fibers, ${ }^{18.19}$ which are concentrated in the globus pallidus. This unique morphology, which characterizes pallidal dendrites, is now termed woolly fibers. ${ }^{21}$ They are composed of an unstained central core (a non-reactive pallidal dendrite), ensheathed in a dense plexus of thin striatal enkephalin-positive efferents (Fig. 1c,d). Evidence that these fibers are indeed pallidal dendrites ensleeved in a plexus of striatal efferents is described in detail elsewhere. ${ }^{21}$ However, briefly stated, the key points are (a) woolly fibers bear a striking resemblance to the Golgi-impregnated pallidal dendrites

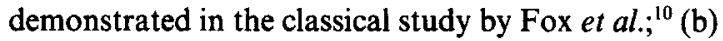
enkephalin-positive woolly fibers disappear in pallidal regions deafferented by striatal lesions; (c) wherever woolly fibers are found, adjacent Nissl sections reveal large pallidal-like neurons; and (d) in all regions where woolly fibers appear outside the conventional pallidal boundaries, they are directly continuous with the main body of the globus pallidus. These fibers have recently been used as a marker for the true extent of the globus pallidus in the rat, ${ }^{21} \mathrm{cat}^{14}$ and primate. ${ }^{22}$ These studies indicate that this structure is much larger than conventionally defined, adding further confirmation to reports demonstrating the ventrorostriatal extention of the globus pallidus which stretches beneath the anterior commissure and into the olfactory tubercle. This region is now referred to as the ventral pallidum. ${ }^{9,24-26,35,39}$ In addition, ramifications were demonstrated extending into the

Please address all correspondence to: S. N. Haber. ventral striatum, the dorsal region of the amygdala, the lateral hypothalamus and a limited area invading the bed nucleus of the stria terminalis.

Two other neuropeptides, substance $P$ and dynorphin, another potent opiate, are also characterized by the pattern of woolly fibers in the globus pallidus. ${ }^{21,22}$ Peptide-positive woolly fibers are not distributed uniformly. Both rich and poor regions have been identified for each peptide. Thus, for example, enkephalin-like immunoreactivity is clearly seen in the external pallidal segment and ventral pallidum, while it is relatively weak in the internal segment. ${ }^{4,8,18,22,26,38}$ Similarly, dynorphin-like immunoreactivity is densely distributed in only certain pallidal regions, primarily in the external segment and the ventral pallidum. ${ }^{4,22,30}$ On the other hand, substance P-like immunoreactivity is concentrated in the internal segment rather than the external segment, while it is also found in the ventral pallidum. ${ }^{18,21}$

The main input to the globus pallidus is from the striatum (for reviews see Refs 3,11,32) and the peptide-positive cell bodies of the striatum are thought to be the source for the peptide-staining seen on pallidal fibers. ${ }^{6,7,21,27}$ Afferents to the rat striatum have been shown to originate both from structures associated with the somatic sensorimotor system and from those associated with the limbic system. These projections terminate in relatively discrete striatal regions, $1,2,13,29.34$ dividing the rat striatum into a dorsolateral division (motor-related) and a ventromedial division including the nucleus accumbens (limbicrelated). Projections from the striatum to the globus pallidus are now known to maintain this functional compartmentalization to some extent. ${ }^{14,24,26,33,40}$ Thus, inputs from the dorsolateral division terminate in the dorsolateral globus pallidus while afferents from the 
ventromedial striatum terminate primarily in the ventral pallidum.

Because of the differential distribution of the three neuropeptides, and the possible functional relationships with respect to circuitry, we undertook this study to determine firstly, the extent of the globus pallidus in man; secondly, the differential distribution of enkephalin, dynorphin, and substance $P$ in this structure; and thirdly, the relationship of these peptide distribution patterns to what is known about limbic vs motor circuitries.

\section{EXPERIMENTAL PROCEDURES}

Three brains from neurologically normal patients were obtained between 8 and $10 \mathrm{~h}$ after death. Coronal slabs of approximately $15 \mathrm{~mm}$ were cut immediately. Tissue was then fixed by immersion in buffered formalin for 2-3 weeks, then transferred to increasing concentrations of sucrose $(5 \%, 10 \%, 20 \%)$ and finally stored in $30 \%$ sucrose in phosphate buffer for 1-3 days. The brains were frozen and cut on a sliding microtome at $50 \mu \mathrm{m}$.

Antisera to enkephalin and substance $P$ were generously provided by Dr. R. Elde, University of Minnesota and Dr. R. Ho, University of Ohio, respectively. Characterization of these antibodies has been described in detail elsewhere. ${ }^{19,28}$ They do not crossreact with each other or dynorphin under immunohistochemical conditions. Antibodies for dynorphin A-(1-17) were directed against the carboxy terminus of dynorphin A and do not crossreact with [Met]enkephalin; [Leu]enkephalin; [Met]enkephalin $-\mathrm{Arg}^{6}-\mathrm{Glu}^{7}-\mathrm{Leu}^{8}$; [Met]enkephalin-Arg ${ }^{6}-P^{7}{ }^{7}$; Peptide E; Bam 22 P. Dynorphin $B, A$ or beta endorphin; adrenocorticotrophic hormone or alpha-melanocyte-stimulating hormone. A modified peroxidase-antiperoxidase technique of Sternberger ${ }^{37}$ as described elsewhere, ${ }^{22}$ was used throughout the present study. Sequential sections were stained with enkephalin, substance $\mathrm{P}$ or dynorphin antisera, additional sections scrved as controls for antisera specificity by preincubating each of the primary antibodies with the corresponding synthetic peptide. These antisera did not crossreact with each other under immunohistochemical conditions. Furthermore, antibodies were generated to a peptide sequence unique to the precursor molecules of enkephalin and dynorphin which did not contain the opiate ligand itself. These antisera showed an identical distribution pattern to that seen with the opiates generated from that molecule. The sections were mounted and dipped in a $0.1 \%$ solution of osmium tetroxide in distilled water for $30 \mathrm{~s}$. This was done to intensify the stain. Alternate sections were stained with Cresyl Violet.

\section{RESULTS}

As has been observed in the rat and monkey, enkephalin-, substance P- and dynorphin-like immunoreactivity are all characterized by the pattern of woolly fibers in the human globus pallidus (Fig. 1). At high magnification, this pattern can be seen to be composed of many individual beaded axons wrapping pallidal dendrites. Enkephalin-positive woolly fibers appear to be more widely and densely distributed than the other two neuropeptides, thus suggesting a greater density of synaptic contacts. None of the three neuropeptides are evenly distributed throughout the globus pallidus. This is true both within the conventional boundaries as well as outside those boundaries.

\section{Within the conventional boundaries}

Both enkephalin- and dynorphin-like immunoreactivity are quite dense in the external segment and relatively weak in the internal pallidal segment (Figs $3 a, c$ and 6). Substance $P$ positivity, on the other hand, is relatively weak in the external segment while strong in the internal segment (Figs $3 b$ and 6 ). Within the external segment, positive staining of both opiate peptides appears to be strong throughout, although some intensity differences can be seen. The staining of the more ventrolateral region appears slightly weaker for both opiates while that of the dorsal and medial regions appears stronger. This is more evident in more caudal sections and in sections with dynorphin antisera (Figs 3 and 6). Although substance P-like immunoreactivity is relatively weak throughout the caudorostral extent of the external pallidum, denser staining can be observed around the perimeter of the nucleus. This is particularly evident in medial and dorsal regions which are adjacent to the internal segment (Figs 3, 6 and 7).

The internal segment of the human globus pallidus is divided into an inner portion and an outer portion by the accessory medullary lamina. Within the two portions of the internal segment, a region of the inner portion shows moderate enkephalin-positive staining thus setting it apart from the remainder of this segment. Dynorphin-positive fibers are also seen here but are much more restricted with respect to area and density (Figs 3 and 6). Substance P-like immunoreactivity is uniformly distributed throughout both portions of the internal segment.

\section{Outside the conventional boundaries}

Woolly fibers protrude into surrounding nuclei from the peptide-rich external pallidal segment, expanding the conventionally accepted pallidal borders. At the level of the central amygdaloid nucleus enkephalin-positive woolly fibers extend medially and laterally from the base of the globus pallidus beneath the ansa lenticularis. A prominent group of woolly fibers continue ventrally and curve around the lateral side of the central nucleus. Joined by a more loosely arranged contingent on the medial side, these enkephalin-rich fibers surround the nucleus (Fig. 2). A few woolly fibers traverse rather than circumvent the nucleus but none extend into more ventral regions. The woolly fibers of the amygdala are clearly distinguishable from the single beaded axons seen in the amygdaloid complex as described by Roberts et al. ${ }^{36}$ Only an occasional dynorphin-positive woolly fiber appears in this region and no substance $P$ fibers are seen here. At this and slightly more rostral levels, single as well as small groups of enkephalin-positive woolly fibers protrude ventrally into the substantia innominata; again neither dynorphin, nor substance $P$ fibers are seen here (Fig. 3). At the intersection of the internal capsule and anterior commissure, fibers containing all three neuropeptides traverse the inter- 
Fig. 1. Light microscopic appearance of woolly fibers. Note the difference between single positive striatal axons (sf) and the plexus formations enmeshing dendrites or woolly fibers (wf): (a) an example of a substance P-positive wf; (b) an example of a dynorphin-positive wf; (c) an example of an enkephalinpositive wf; (d) enkephalin-positive fibers enmeshing a pallidal neuron as well as its dendrites.

$\begin{array}{llll}\text { Abbreviations used in figures: } & \text { GPi } & \text { globus pallidus (internal segment) } \\ \text { AC. anterior commissure } & \text { IC } & \text { internal capsule } \\ \text { AmC nucleus centralis amygdalae } & \text { NAc } & \text { nucleus accumbens septi } \\ \text { BNST bed nucleus of stria terminalis } & \text { P } & \text { putamen } \\ \text { CD } & \text { caudate nucleus } & \text { SI } & \text { substantia innominata } \\ \text { GPe } & \text { globus pallidus (external segment) } & \text { VP } & \text { ventral pallidum }\end{array}$

Fig. 2. Enkephalin-positive staining in a $50 \mu \mathrm{m}$ coronal section through the basal ganglia of the human. Note how the woolly fiber pattern of staining extends medially from the external segment of the globus pallidus into the substantia innominota and continues ventralward, almost completely surrounding the central amygdaloid nucleus. Not all the positive staining in the vicinity of the central amygdaloid nucleus is derived from woolly fibers. Many of the fibers are single axons presumably from the intrinsic neurons of the amygdala. The woolly fibers are concentrated in the region indicated by the arrowheads.

Fig. 3. Enkephalin (a), substance $P$ (b) and dynorphin (c) staining on adjacent $50 \mu \mathrm{m}$ sections of human tissue. Asterisks indicate blood vessels. In (a) arrowheads indicate wf in the BNST; in (b) and (c) arrowheads indicate the lack of staining in the same regions. Open arrows compare differences in staining in the substantia innominota.

Fig. 4. Enkephalin (a), substance $P(b)$ and dynorphin (c) staining on adjacent $50 \mu \mathrm{m}$ sections at the level of the anterior commissure. Note the pattern differences between the peptides in the ventral pallidum. Enkephalin-positive staining is much more widespread in this ventral region. There are numerous cell bodies labeled with dynorphin antibody in the subcommissural forebrain area (not clearly discernible at this magnification). Thus, all staining should not be interpreted as woolly fibers. Woolly fibers are indicated by the arrowheads.

Fig. 5. Rostral section stained for enkephalin. Arrows indicate the dense woolly fibers which are still seen at this level. Note that many fibers are embedded in the internal capsule. Enkephalin staining in the striatum is very patchy as indicated in previous reports. ${ }^{10}$

Fig. 6. Schematic drawing showing the distribution of enkephalin (a) substance $P$ (b) and dynorphin (c) at a similar level as Fig. 3; (d) represents all three peptides viewed together. Note the relatively sparse peptide staining in the ventrolateral portion of the external segment and in the lateral part of the internal segment.

Fig. 7. Schematic drawing showing the distribution of enkephalin (a), substance $P(b)$ and dynorphin (c) just caudal to the crossing of the $\mathrm{AC}$; (d) represents all three peptides viewed together. Note how the peptide staining is concentrated in the very medial portion of the external segment adjacent to the internal capsule.

Fig. 8. Schematic drawing showing the distribution of enkephalin (a); substance $P$ (b); and dynorphin (c) at the level of the AC decussation; (d) represents all three peptides viewed together. Note substance $P$ and dynorphin appear to be concentrated in different regions of the ventral pallidum. 

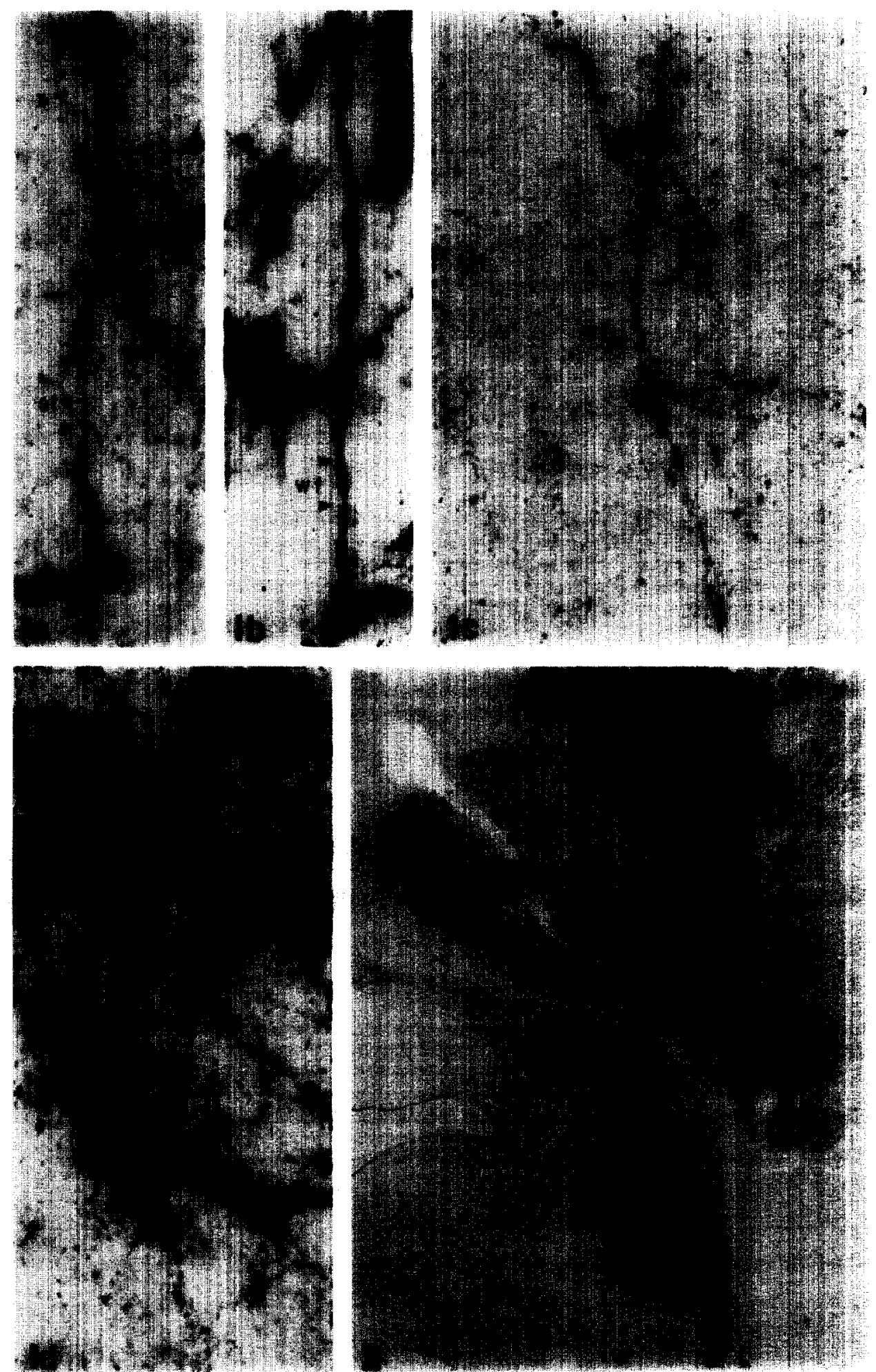

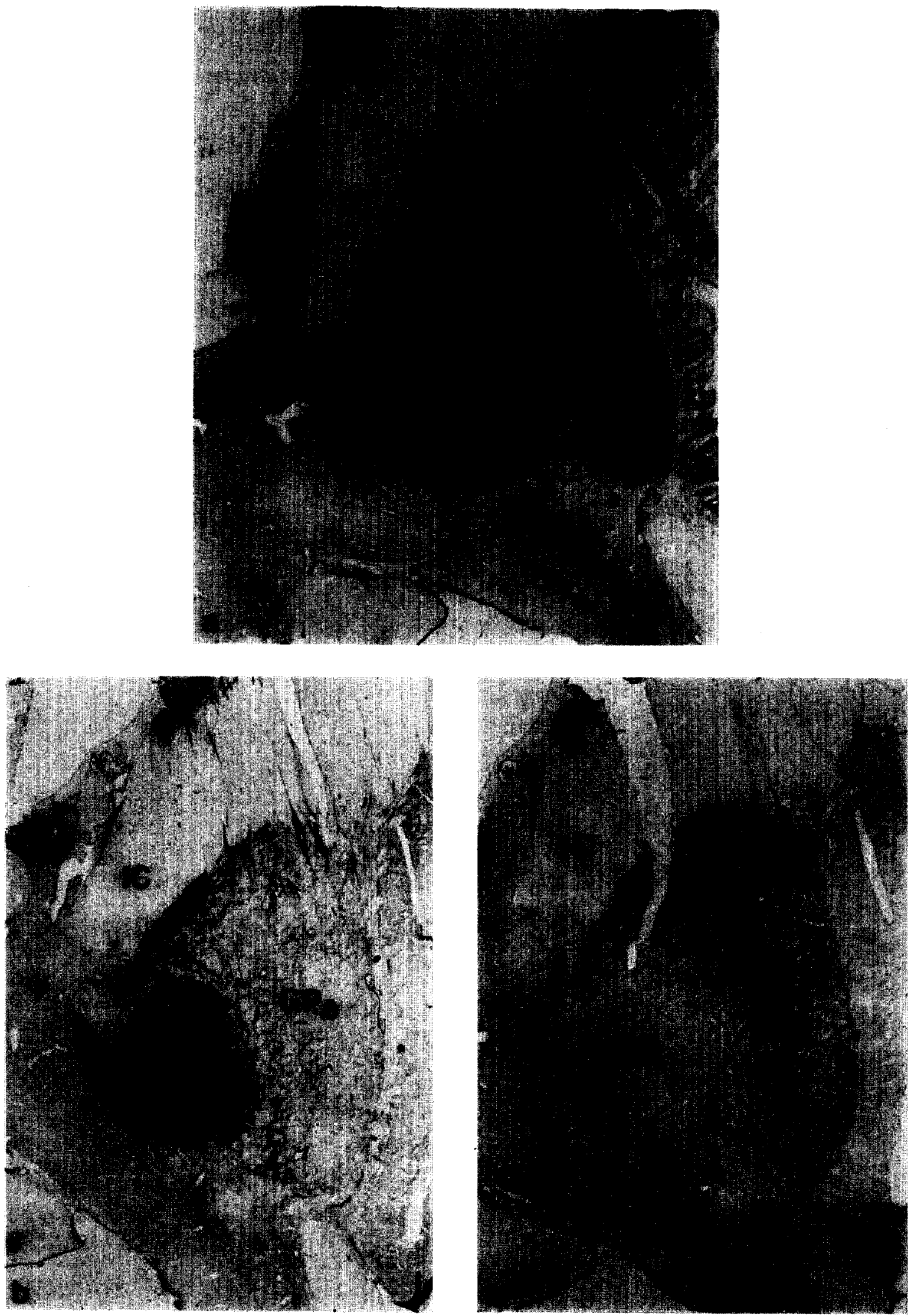

Fig. 3. 

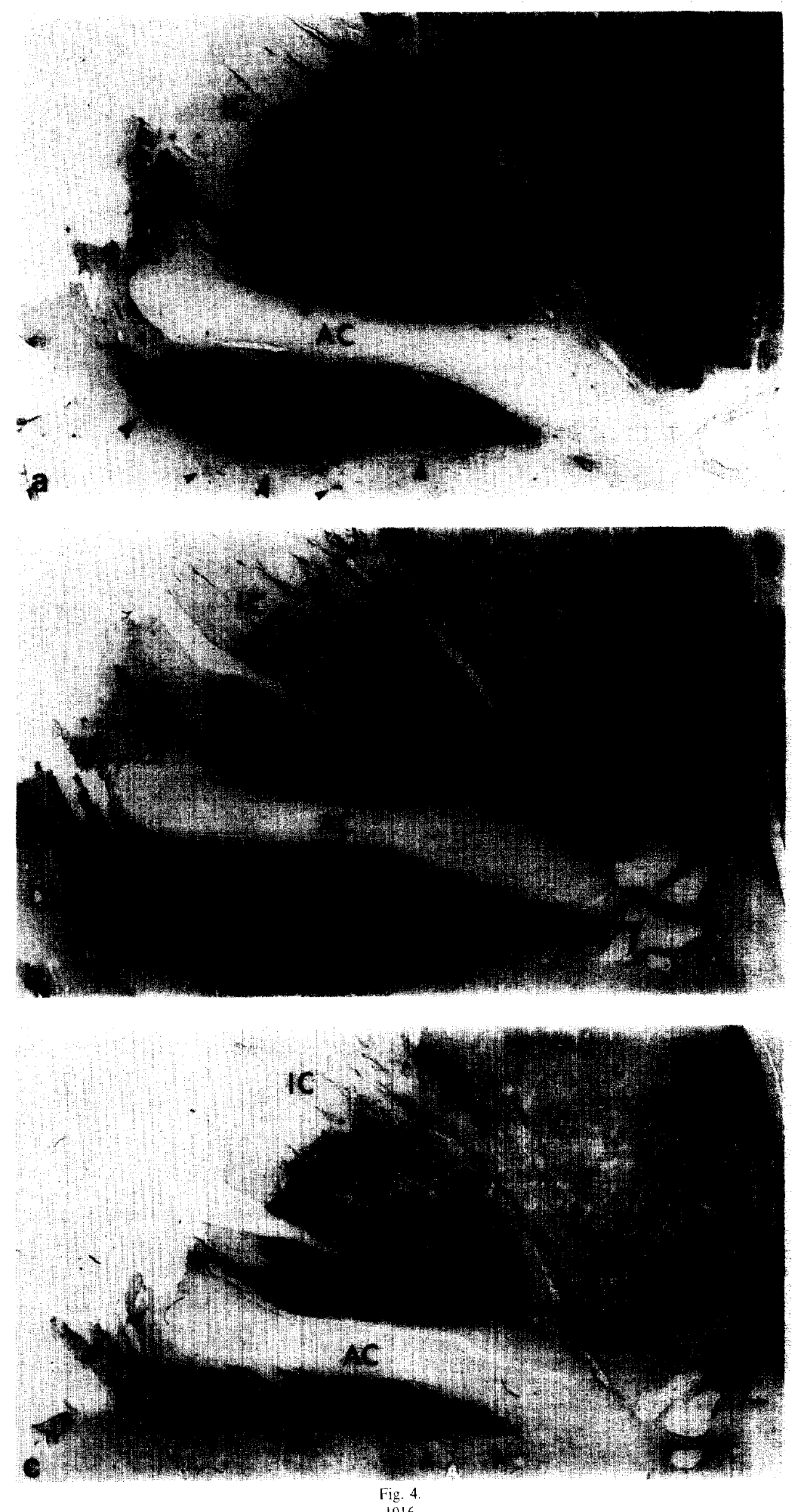


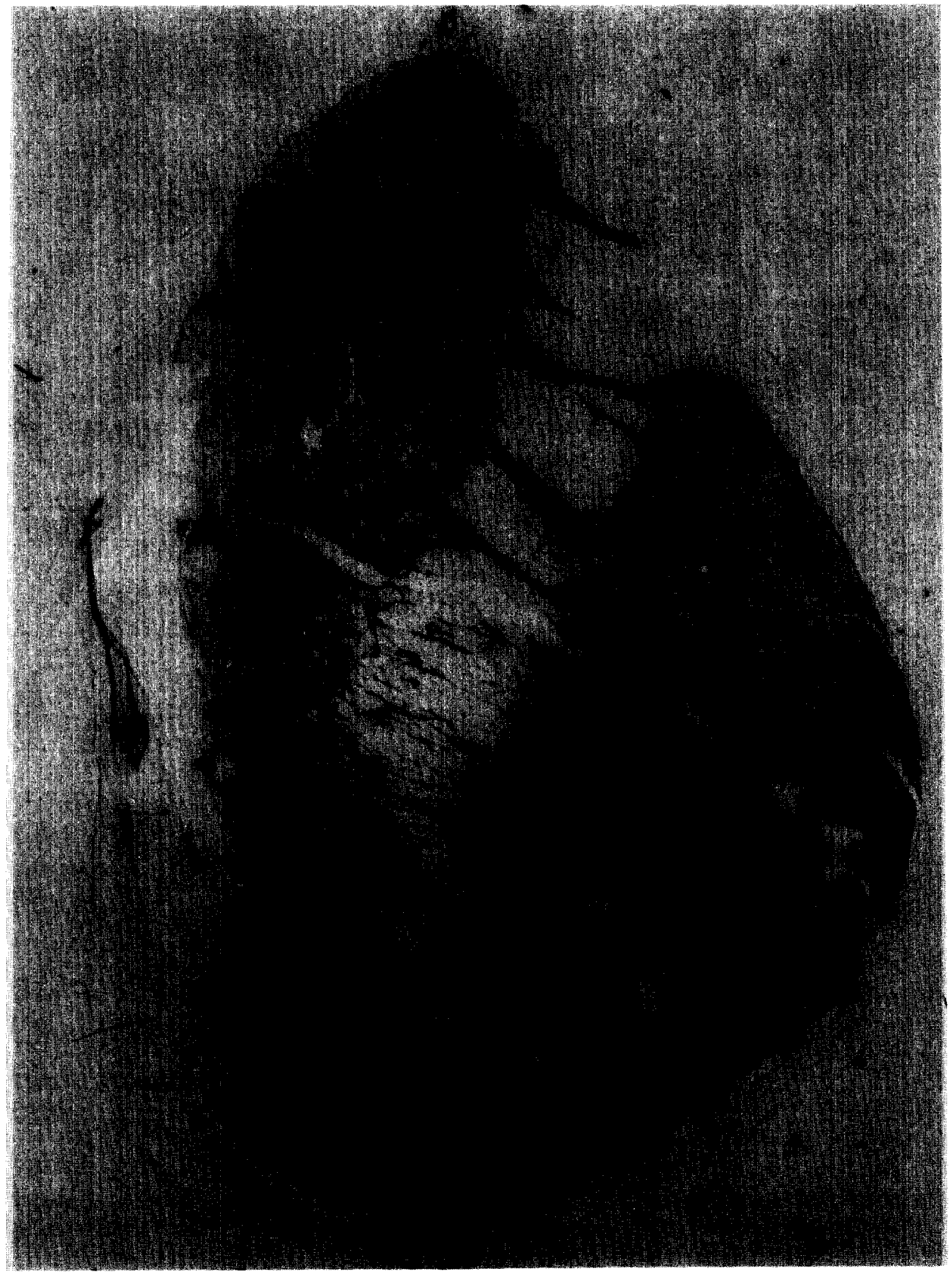

Fig. 5. 

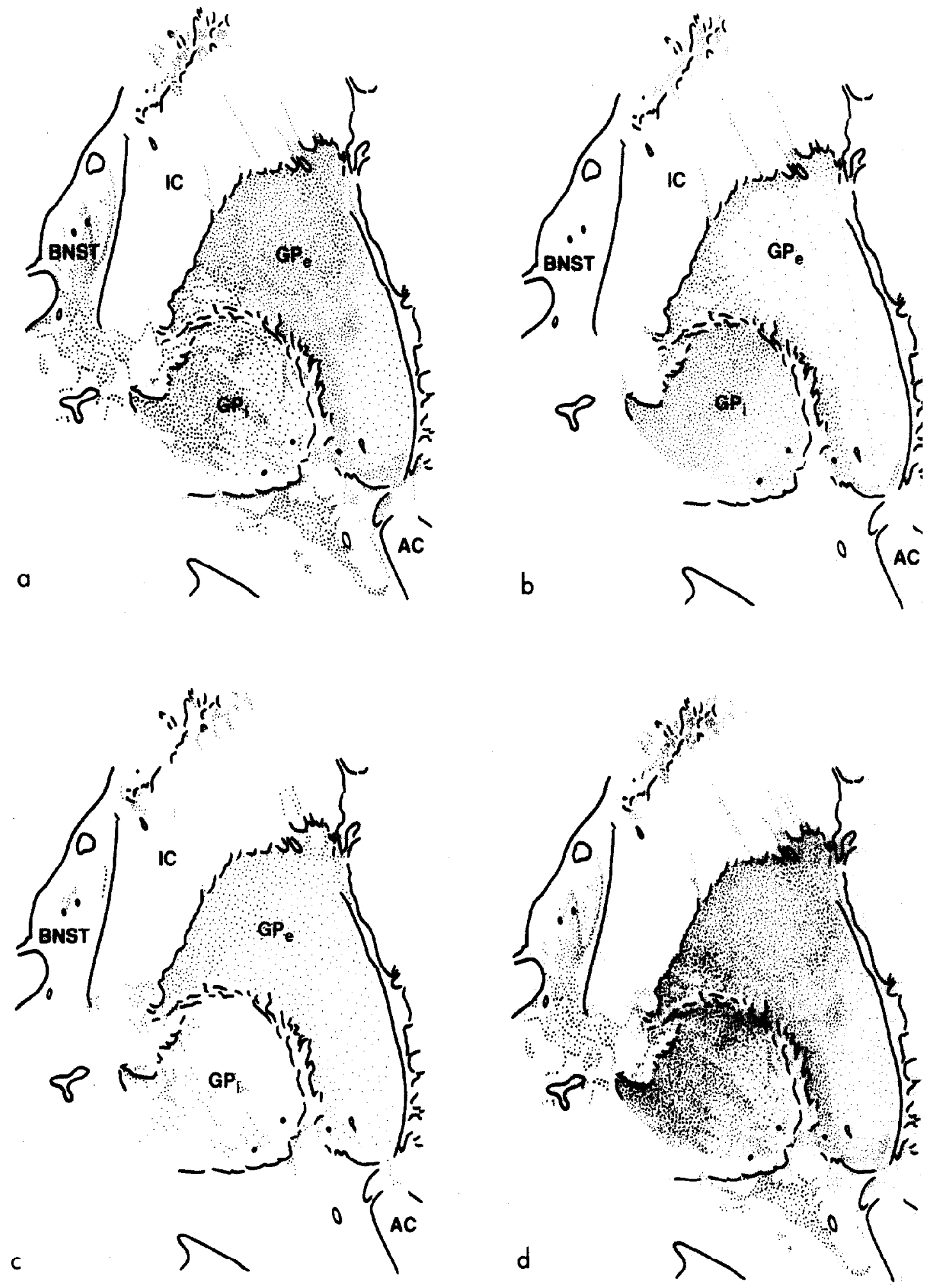

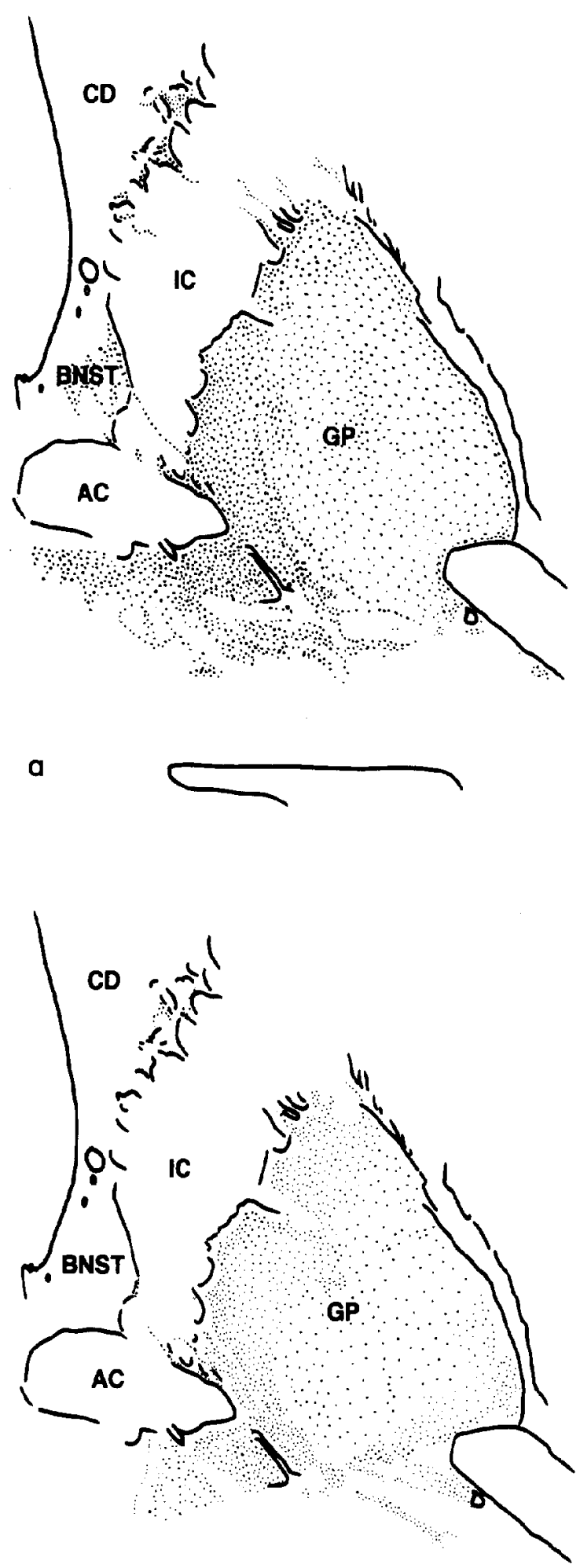

$c$

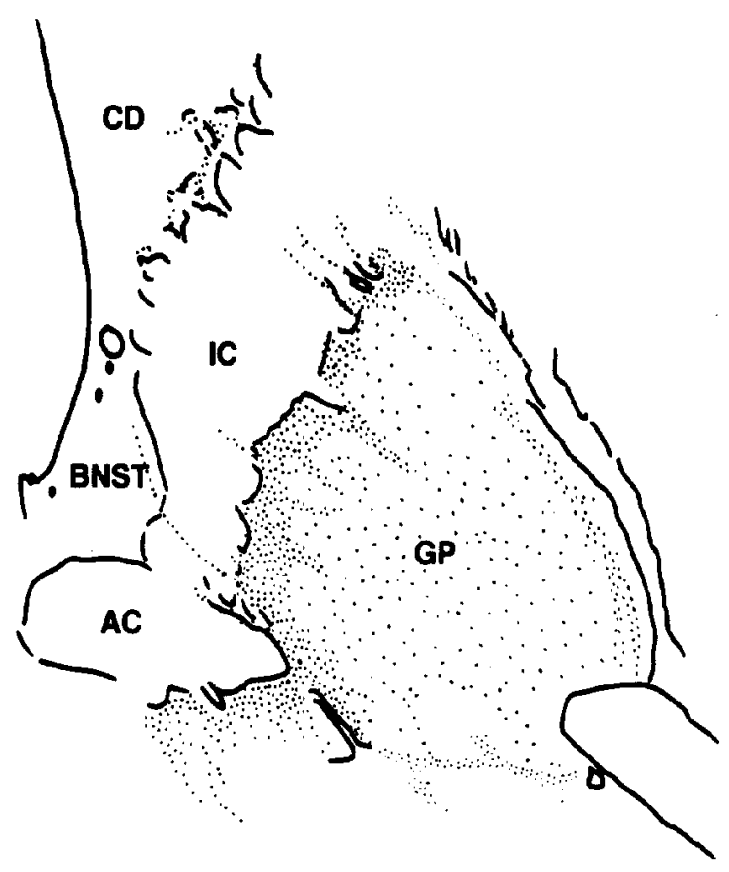

b

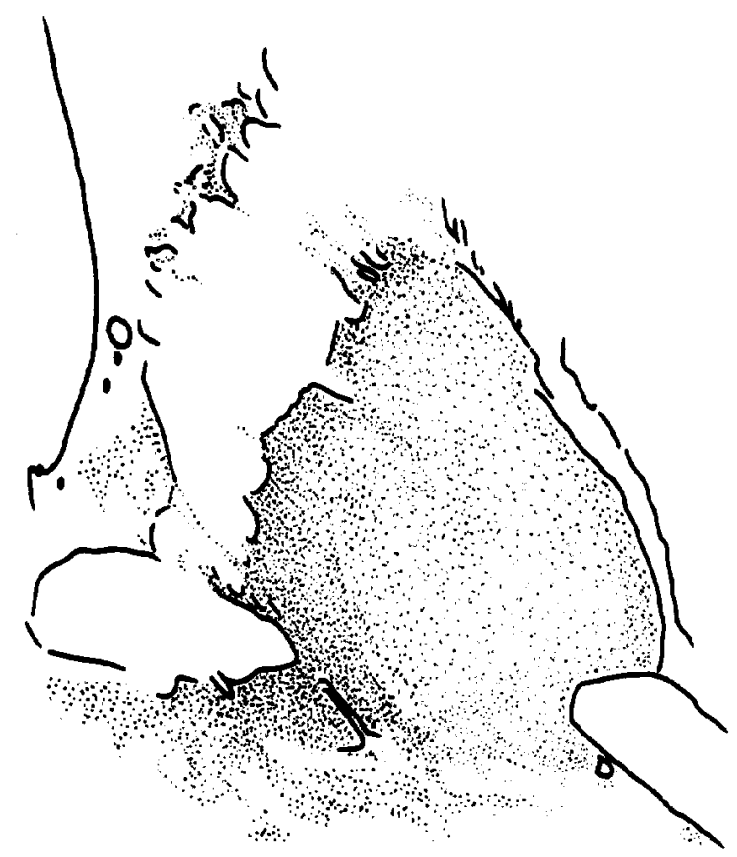

d

Fig. 7.

1019 

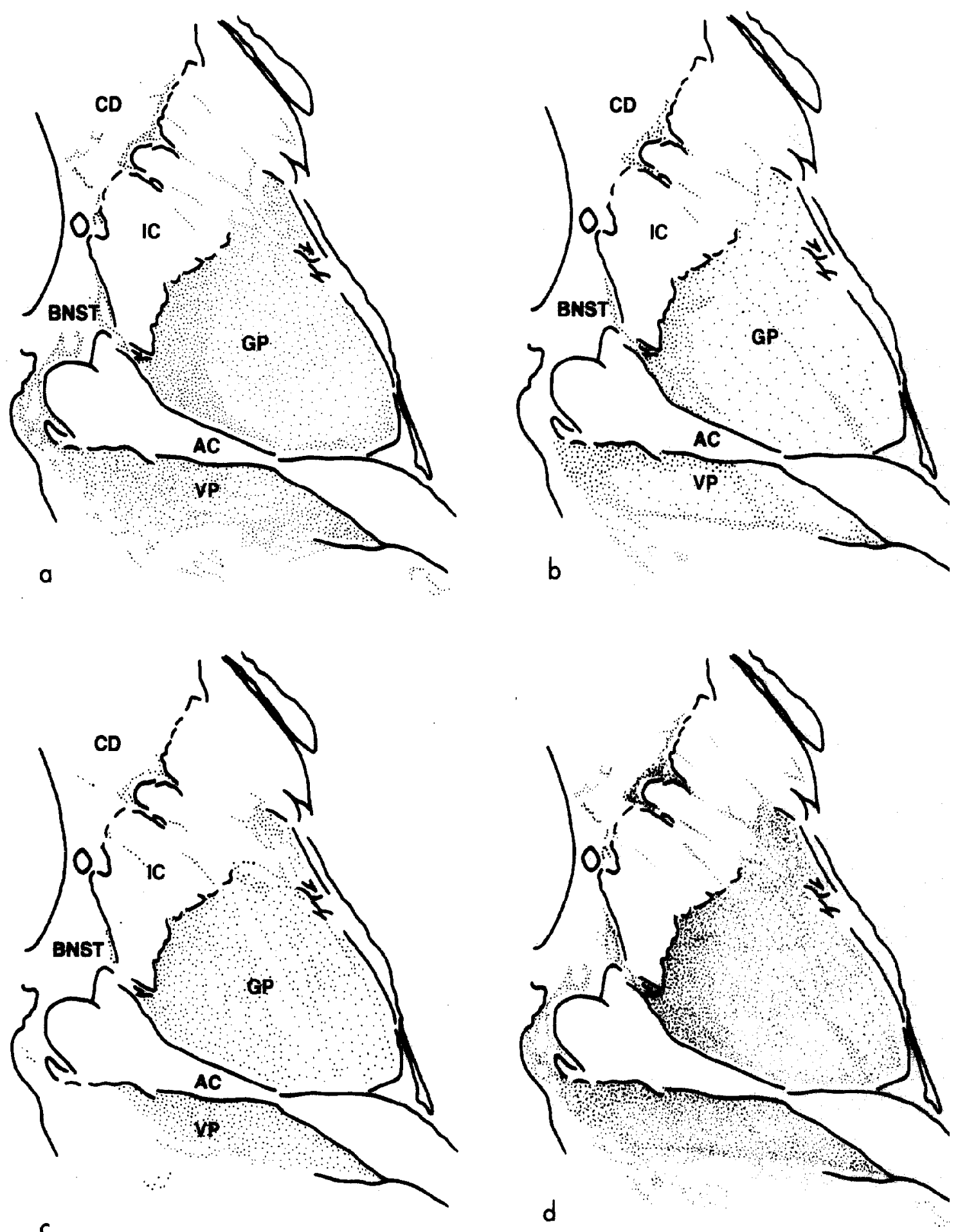
nal capsule into the bed nucleus of the stria terminalis, forming a thin stratum covering the medial surface of the internal capsule (Figs 3 and 7).

The most massive expansion of pallidal woolly fibers begins caudal and ventral to the anterior commissure and stretches anteriorly through the nucleus accumbens. All three neuropeptides are dense in this large ventral pallidal area (Figs 4 and 8); however, enkephalin fibers are the most widely distributed. Directly beneath the commissure, dense enkephalin-like immunoreactivity extends ventrally and medially, thus occupying a rather substantial area. Dynorphin-positive woolly fibers are primarily confined to the region directly ventral to the external pallidal segment. While there is some overlap, substance P-like immunoreactivity appears to be ventral and medial to the subcommissural dynorphinpositive fibers. Neither of these two peptides extend outside the boundaries of the enkephalin-positive staining (Figs 4 and 8).

Caudal to the anterior commissure, a distinct cluster of enkephalin-rich woolly fibers is seen ventral to the internal capsule, curving dorsalward around the capsule to invade the subcommissural bed nucleus of the stria terminalis (Figs 3 and 6). Within this supracommissural nucleus, a dense swirl of enkephalin-positive woolly fibers encapsulates and, in lesser density, permeates a large ovoid cell island centrally located in the bed nucleus of the stria terminalis. This island is rich with enkephalinpositive cell bodies. As seen in the amygdala, these woolly fibers are distinct from the single enkephalinpositive axons seen in the bed nucleus of the stria terminalis. ${ }^{41}$ Very few dynorphin-positive fibers are found here and there is no clear evidence of substance P-like immunoreactivity.

At more rostral levels, enkephalin- and dynorphinpositive pallidal fibers follow the anterior commissure as it crosses the internal capsule and dense staining is seen on both sides of the capsule as well as traversing it (Fig. 5). Here numerous enkephalin-positive fibers are also scattered throughout the ventral striatal region including the nucleus accumbens, the olfactory tubercle, the caudate nucleus and the laterally adjacent parts of the putamen. A few dynorphin-positive fibers are confined to the nucleus accumbens and caudate nucleus.

\section{DISCUSSION}

\section{Differential peptide distributions}

Of the three neuropeptide fibers, enkephalinpositive woolly fibers are the most widely spread and show the most intense stain both within and outside the conventional boundaries of the globus pallidus.

Within the conventional boundaries. Enkephalin and dynorphin woolly fiber distribution within the conventional boundaries of the globus pallidus are quite similar. Both are more densely distributed in the external segment than in the internal segment, and within the external segment relatively weaker staining is observed in the same lateral portion. While some dynorphin-like immunoreactivity is clearly observed in the inner portion of the internal segment, it is considerably weaker and less extensive than enkephalin-like immunoreactivity. Substance P-like immunoreactivity distribution, on the other hand, is quite weak (with the exception of the perimeter) in the external segment, while it is uniformly dense in the internal segment. The fact that this is the opposite of what is seen with the opiate peptide distributions has already been described in nonhuman primates and discussed with respect to circuitry. ${ }^{18}$ It is noteworthy that the very medial portion of the external segment, adjacent to the internal capsule, is particularly rich in all three peptides (Figs 7d and 8d).

Outside the conventional boundaries. Neither dynorphin- nor substance P-positive fibers are found in regions which do not contain enkephalin. However, a number of areas which are positive for enkephalin are dynorphin- and substance P-negative (Figs 6-8d).

The external pallidal segment, as seen with enkephalin-positive woolly fiber distribution, extends outside the conventional boundaries of the globus pallidus in ventral, medial and rostral directions, invading the amygdaloid complex, the olfactory tubercle, the bed nucleus of the stria terminalis and the ventral striatum. These findings agree well with earlier observations in the rat ${ }^{21}$ (see also Refs 9, 26, 35 and 39) and monkey. ${ }^{22}$ There are two notable exceptions. The sharply defined enkephalin-positive ovoid island in the supracommissural bed nucleus and the extensive enkephalin-like immunoreactivity in the subcommissural bed nucleus appear to be unique to human tissue (Figs $3 \mathrm{a}$ and $6 \mathrm{~d}$ ). No comparable staining pattern was found in this region of other species.

Contrasts in the distribution of the three neuropeptides are quite evident outside the conventional pallidal boundaries. There seems to be very little substance P- or dynorphin-like immunoreactivity in most of the "extra" pallidal regions such as the amygdaia, bed nucleus of the stria terminalis (Fig. 6d), or striatum. Only the ventral pallidum shows dense staining of all three substances, and within this substructure, neither substance $P$ nor dynorphin are distributed throughout. Dynorphin woolly fibers are observed in a restricted central region directly beneath the anterior commissurc and do not spread medially into the subcommissural bed nucleus of the stria terminalis, or ventrally deep into the olfactory tubercle (Figs 6-8c). It is noteworthy that substance $P$ fibers show a more extensive medial and ventral subcommissural distribution, but are conspicuously lacking in the central region (Fig. 8b). This is quite unlike the ventral pallidum of the rat where substance P-like immunoreactivity is dense throughout this subcommissural structure. ${ }^{21}$ It could be suggested that the area defined as the dorsal 
pallidum in the rat and receiving input from the caudate nucleus rather than from the nucleus accumbens is, in primates, larger, and extends beneath the anterior commissure, thereby pushing the ventral pallidum, or that region which receives input from the nucleus accumbens, ventralward. Support for this idea comes from tritiated amino acid injections confined to the caudate nucleus of the cat. The label was seen to extend beneath the commissure, but not beyond the dorsal and central aspect. ${ }^{4}$ This reasoning would suggest that dynorphin is restricted in the rat to the dorsal pallidum. However, this is not the case, since dynorphin-positive fibers are relatively dense in the ventral pallidum of the rat. It raises the interesting question of what arca in the primate forebrain is homologous with the ventral pallidum of the rat.

\section{Functional considerations}

The distribution of peptide-positive woolly fibers outside the conventional boundaries of the globus pallidus has important implications for the function of the human basal ganglia. Both the main body of the external segment and the internal segment of the globus pallidus are generally associated with the motor system, although at least one efferent projection, to the lateral habenular nucleus from the internal segment, might be considered within the realm of the limbic system. The external pallidal segment, however, extends in ventral, medial and rostral directions, invading the amygdaloid complex, the olfactory tubercle, the bed nucleus and the ventral striatum, areas related to the limbic rather than the motor system. While there is no direct evidence that these woolly fibers actually receive limbic information or that the cells on which they synapse project to limbic related areas, evidence from tract-tracing studies in the rat are highly suggestive.

In a previous paper we suggested that the enkephalin-rich woolly fibers in the rat amygdala represent a projection from the most ventral part of the striatum. ${ }^{21 *}$ This receives support studies tracing the efferent connections of the ventral striatum..$^{14,33,40}$ Immediately caudal to the anterior commissure enkephalin-, substance $P$ - and dynorphin-positive woolly fibers traverse the internal capsule to invade the bed nucleus of the stria terminalis; this pattern corresponds closely to fiber labeling found in the rat

*As described in detail elsewhere, inputs from the limbic system terminate throughout the entire ventromedial portion of the striatum which includes the nucleus accumbens, the olfactory tubercle, as well as the ventromedial caudate putamen, while motor-related afferents project to the more dorsolateral portion of the striatum. ${ }^{2 y}$ This ventromedial part of the striatum stands apart from the motor innervated dorsolateral part by virtue of its innervation from the hippocampus, amygdala, frontal cortex, cingulate gyrus, the ventral tegmental area of Tsai and the dorsal raphe nucleus of the mesencephalen, all limbic-related structures. bed nucleus with a tritiated amino acid injection into the nucleus accumbens. ${ }^{33}$

The most massive pallidal extension, the ventral pallidum, is rich in all three neuropeptides. Experimental evidence in the rat indicates that the main body of the ventral pallidum receives its input from the nucleus accumbens, ${ }^{14,24.26,33.40}$ while the most ventrally located portions are thought to receive their afferents from striatal neurons of the olfactory tubercle. ${ }^{25.35}$ Lesions in these areas of the rat deplete enkephalin- and substance P-like immunoreactivity in the ventral pallidum in a topographic fashion. ${ }^{21}$ The oval island of enkephalin-positive woolly fibers in the bed nucleus of the stria terminalis has been found only in human brains; and consequently, animal experiments cannot give us a clue to their striatal source. This configuration, however, is lacking from brains in advanced stages of Huntington's chorea (S. N. Haber, unpublished observations) whereas it appears normal in earlier stages of the disease. This would suggest that these afferents arise from the nucleus accumbens since the striatal degeneration, which characterizes the disease, is known to affect the nucleus accumbens only in its later stages.

These results show that the human globus pallidus is a larger and more intricately shaped structure than previously thought. It ramifies into several limbicrelated structures and parallel animal experiments strongly suggest that these areas receive input from the limbic-afferented portions of the striatum. Based on their localization in limbic-related neuropil, it is likely that these pallidal neurons engage, at least in part, in limbic circuitry. Recent studies have provided some support for this hypothesis. ${ }^{15.20}$ Anterograde studies of the ventral pallidum have shown that this area projects to the dorsomedial nucleus of the thalamus, the ventral tegmental area of Tsai, the ventral striatum and the lateral habenular nucleus. Furthermore, choline acetyltransferase- and acetylcholinesterase-positive neurons in this region, which project to the amygdala, ${ }^{16.31 .42}$ lie embedded in the network of peptide-posilive woolly fibers. ${ }^{17,23}$

Finally, the fact that the distribution of the three neuropeptide-positive woolly fibers coincides in some limbic related pallidal areas while not in others suggests regional differences in peptide cell distribution in the striatum; thus some regions might contain enkephalin-positive cells and few or no substance $P$ and dynorphin neurons, while other areas contain all three. Patches of peptide-positive regions in the ncostriatum have been well documented.,12 Thus areas of the striatum which, for example, project to the globus pallidus located in the bed nucleus of the stria terminalis, olfactory tubercle and amygdala do not appear to use dynorphin or substance $P$ as a modulator, while those projection to regions of the ventral pallidum might use all three. Alternatively peptidecontaining striatal neurons could be relatively evenly distributed throughout the striatum but project differentially to the globus pallidus. In either case it 
is clear that enkephalin-positive woolly fibers are far more widespread and therefore likely to receive input from all parts of the striatum.

Acknowledgements-We thank Dr. W. J. H. Nauta for discussing and reviewing this paper, Dr. N. Kowell for supplying us with normal brains, the Brain Tissue Resource Center, McLean Hospital, Belmont, Massachusetts, for supplying us with pathological brains and J. Schu for her valuable technical assistance. This study was supported by NIH grant No. 5-R23-NS20467-02 and a grant from the Scottish Rite Schizophrenia Program to S.N.H. and NIDA grant Nos DA02265 and DA00154 to S.J.W.

\section{REFERENCES}

1. Beckstead R. M., Domesick V. B. and Nauta W. J. H. (1979) Efferent connections of the substantia nigra and ventral tegmental area in the rat. Brain Res. 175, 191-217.

2. Beckstead R. M. (1979) An autoradiographic examination of corticocortical and subcortical projections of the mediodorsal-projection (prefrontal) cortex in the rat. J. comp. Neurol. 184, 43-62.

3. Carpenter M. B. (1976) Anatomical organization of the corpus striatum and related nuclei. In The Basal Ganglia (ed. Yahr M.P.), pp. 1-36. Raven Press, New York.

4. Chesselet M. F. and Graybiel A. M. (1983) Met-enkephalin-like and dynorphin-like immunoreactivities of the basal ganglion of the cat. Life Sci. 33, suppl. 1, 37-40.

5. Corsellis J. A. N. (1976) In Ageing and the Dementias. Greenfield's Neuropathology (eds Blackwood W. and Corsellis J. A. N.). E. Arnold, London.

6. Cuello A. C. and Paxinos G. (1978) Evidence for a long leu-enkephalin striopallidal pathway in rat brain. Nature 271, $178-180$.

7. Del Fiacco M., Paxinos G. and Cuello A. C. (1982) Neostriatal enkephalin-immunoreactive neurons project to the globus pallidus. Brain Res. 231, 1-17.

8. Elde R., Hökfelt T., Johansson O. and Terenius L. (1976) Immunohistochemical studies using antibodies to leucine-enkephalin: initial observations on the nervous system of the rat. Neuroscience, 1, 349-351.

9. Fallon J. H. and Ribak C. E. (1980) Multipie neurotransmitter studies in the islands of Calleja complex of the basal forebrain. III. Connections, correlations, and reservations. Soc. Neurosci. Abstr. 6, 114.

10. Fox C. H., Andrade H. N., du Qui I. J. and Rafols J. A. (1974) The primate globus pallidus. A golgi and electron microscope study. J. Fur. Hirnforscheng 15, 75.

11. Graybiel A. M. and Ragsdale C. W. (1979) Fiber connections of the basal ganglia. Prog. Brain Res. 52, $239-284$.

12. Graybiel A. M., Ragsdale C. W., Jr., Yoneoka E. S. and Elde R. P. (1981) An immunohistochemical study of enkephalins and other neuropeptides in the striatum of the cat with evidence that the opiate peptides are arranged to form mosaic patterns in register with the striosomal compartments visible by acetylcholinesterase staining. Neuroscience 6, 377-397.

13. Groenewegen H. J., Arnolds D. E. A. T. and Lopes da Silva F. H. (1981) Afferent connections of the nucleus accumbens in the cat with special emphasis on the projections from the hippocampal regions-an anatomical and electrophysiological study. In Nucleus Accumbens (eds de France J. and Chronister R.). Rockland, Maine.

14. Groenewegen H. J. and Russchen F. T. (1984) Organization of the efferent projections of the nucleus accumbens to pallidal, hypothalamic and mesencephalic structures. A tracing and immunohistochemical study in the cat. $J$. comp. Neurol. 223, 347-367.

15. Groenewegen H. J. and van Dijk C. A. (1985) Efferent projections of ventral pallidum in the rat as studied with the anterograde transport of phaseolus vulgaris leucoagglutinin (PHA-L). Soc. Neurosci. Abstr. In press.

16. Grove E. A., Haber S. N., Domesick V. B. and Nauta W. J. H. (1983) Differential projections from AChE-positive and AChE-negative ventral pallidum cells in the rat. Soc. Neurosci. Abstr. 9.

17. Grove E. A. and Nauta W. J. H. (1985) Light microscopic evidence for striatal and amygdaloid input to cholinergic cell groups $\mathrm{Ch} 4$ in the rat. Soc. Neurosci. Abstr. In press.

18. Haber S. and Elde R. (1981) Correlation between met-enkephalin and substance P immunoreactivity in the primate globus pallidus. Neuroscience 6, 1291-1298.

19. Haber S. and Elde R. (1982) The distribution of enkephalin immunoreactive fibers and terminals in the monkey central nervous system: an immunohistochemical study. Neuroscience 7, 1049-1095.

20. Haber S. N., Groenewegen H. J. and Nauta W. J. H. (1982) Efferent connections of the ventral pallidum in the rat. Soc. Neurosci. Abstr., 8.

21. Haber S. N. and Nauta W. J. H. (1983) Ramifications of the globus pallidus in the rat as indicated by patterns of immunohistochemistry. Neuroscience 9, 245-260.

22. Haber S. N. and Watson I. W. (1983) The comparison between enkephalin-like and dynorphin-like immunoreactivity in both monkey and human globus pallidus and substantia nigra. Life Sci. 33, Suppl. 1.

23. Haber S. N. (1985) Striatal input to a basal forebrain AChE-positive cell group sets it apart from the rest of the forebrain cholinergic neurons. Soc. Neurosci. Abstr. In press.

24. Heimer L. and Wilson R. D. (1975) The subcortical projections of the allocortex: similarities in the neural associations of the hippocampus, the piriform cortex, and the neocortex. In Golgi Centennial Symposium: Perspectives in Neurobiology. (ed. Santini M.), pp. 177-193. Raven Press, New York.

25. Heimer L. (1978) The olfactory cortex and the ventral striatum. In Limbic Mechanisms (eds Livingston K. E. and Hornykiewicz O.), pp. 95-187. Plenum Press, New York.

26. Heimer L., Switzer R. D. and Van Hoesen G. W. (1982) Ventral striatum and ventral pallidum. Components of the motor system? Trends Neurosci. 5, 83-87.

27. Hong T. S., Yang H. Y. T. and Costa E. (1977) On location of methionine enkephalin neurons in rat striatum. Neuropharmacology 16, 450-453.

28. Ho R. H. and dePalatis L. R. (1980) Substance P immunoreactivity in the median eminence of the North American apossum and domestic fowl. Brain Res. 189, 565-569.

29. Kelley A. E., Domesick V. B. and Nauta W. J. H. (1982) The amygdalostriatal projection in the rat-an anatomical study by anterograde and retrograde tracing methods. Neuroscience 7, 615 . 
30. Khachaturian H., Watson S. J., Lewis W. E., Coy D., Goldstein A. and Akil H. (1982) Dynorphin immunocytochemistry in the rat central nervous system. Peptides 3,941.

31. Nagai T., Kimura H., Maeda T., McGeer P. L., Peng F. and McGeer E. G. (1982) Cholinergic projections from the basal forebrain of rat to the amygdala. $J$. Neuroscience 2, 513-520.

32. Nauta W. J. H. and Mehler M. R. (1966) Projections of the lentiform nucleus in the monkey. Brain Res. 1, 3.42.

33. Nauta W. J. H., Smith G. P., Faull R. L. M. and Domesick V. B. (1978) Efferent connections and nigral afferents of the nucleus accumbens septi in the rat. Neuroscience 3, 385-401.

34. Nauta W. J. H. and Domesick V. B. (1978) Crossroads of limbic and striatal circuitry: hypothalamic-nigral connections. In Limbic Mechanisms (eds Livingston K. E. and Hornykiewicz O.), pp. 75-93. Plenum Press, New York.

35. Ribak C. E. and Fallon J. H. (1983) The islands of Calleja. Complex of rat basal forebrain. I. Light and electron microscopic observations. J. comp. Neurol. 205, 207-218.

36. Roberts G. W., Woodhams P. L., Polak J. M. and Crow T. J. (1982) Distribution of neuropeptides with limbic system of the rat: The amygdaloid complex. Neuroscience 7, 99-131.

37. Sternberger L. A. (1979) Immunocytochemistry. Wiley, New York.

38. Switzer R. C., Hill J. and Heimer L. (1982) The globus pallidus and its rostroventral extension into the olfactory tubercle of the rat: Cyto and Chemoarchitectural Study. Neuroscience 7, 1891-1904.

39. Switzer R. C. and Hill J. (1979) Globus pallidus component in the olfactory tubercle: evidence based on iron distribution. Soc. Neurosci. Abstr. 5, 79.

40. Williams D. J., Crossman A. R. and Slater P. (1977) The efferent projections of the nucleus accumbens in the rat. Brain Res. 130, 217-227.

41. Woodhams J. M., Roberts G. W., Polak J. M. and Grow, T. J. (1983) Distribution of neuropeptides in the limbic system of the rat: the bed nucleus of the stria terminalis, septum, and preoptic area. Neuroscience 8, 677-704.

42. Woolf N. J. and Butcher L. L. (1982) Cholinergic projections to the basolateral amygdaloid: a combined Evans Blue and acetylcholinesterase analysis. Brain Res. Bull. 8, 751-763.

\section{(Accepted 18 September 1984)}

Note added in proof. Upon completion of this paper for publication, an article appeared [Beach and McGeer, Neuroscience (1984) 13, 29-52] describing the distribution of substance P-positive woolly fibers in the primate basal ganglia. 